\title{
Analysis of fixations while solving a test question related to computer networks
}

\author{
Tibor UjbánYi, József Katona And Attila KővÁRI
}

\begin{abstract}
Examination of human eye move is useful because by eye tracking and definition of visual attention, may making conclusions about hidden cognitive processes which are harder to examine. With human eye tracking, visual attention can be defined, therefore hidden cognitive processes may be revealed and examined. The goal of the research, presented in this article, to analyze the so called fixation eye movement parameter recorded during a test question related to computer networks. The paper present what significant differences detected between pre-knowledge and the number of fixations using statistical analysis. The results show a moderately relationship between previous knowledge and fixation counts.
\end{abstract}

Key words and phrases: human-computer interaction, eye-tracking, learning.

ZDM Subject Classification: D60.

\section{Introduction}

In the past few decades, the number of examination methods about eye tracking has been significantly increasing. Our modern technology helps us to better understand the development process of cognitive skills by applying new methods and other approaches, as well as having exact data. By examining the eye motion by instruments, we can observe the learning process and its basic factors. In the learning process, people most likely visually receive information, so the efficiency of visual information processing is a key factor regarding the success 
of learning process. In observing learning-education processes, improving educational efficiency, examinations of human-computer interaction may provide new opportunities. In the interaction between human and computer (as two systems), human behaviour, interaction plays a major role, which may be examined in several ways, either by brain activity [1],[2],[3], VRs [4] or even eye tracking [5]. The human-computer interaction itself deals with such a field of science, that affects the design and implementation of interactive computers made for human sand researches the main relating phenomena [6]. Eye tracking is so significant, because computer users receive most information through visual stimuli as information channels [7]. Examination of human eye move is useful, because by eye tracking and definition of visual attention, we may make conclusions about hidden cognitive processes, which are harder to examine. With human eye tracking, visual attention may be defined, therefore hidden cognitive processes may be revealed and examined. Eye tracking researches are based on the results of eye tracking. Using eye tracking, the geometric location of human visual focal point may be defined during observing each object. Eye tracking also enables the observation of the route of the look, including the definition of which detail is observed for a longer period of time. Based on these parameters, we can examine how visual stimuli correlate with the performance of a particular task, which are less examinable using other methods, and we may get a more accurate image about the correlation with cognitive processes. The above mentioned cognitive processes are affected by visual information perceived by the eye, so these connections are important [8].

The operation of visual system, perception of visual stimuli

Human eye is our visual sense, which - just like a camera - detects light beams coming (or reflected) from the environmental objects, and it models their shape, spatial location and colour. This visual stimulus is forwarded to the central nervous system, where it is processed, and becomes conscious if necessary. In humans, vision plays a major role in receiving information about the environment and adapting to that. Visual information entering into our eye is detected by the retina situated on the back of the eyeball (Figure 1). The most sensitive part of the retina is the fovea, which is surrounded by the parafoveal and the peripheral area. Vision is the sharpest on the fovea area, while the parafovea detects much blurrier image, and peripheral areas receive blurry, hard to recognise stimuli. 


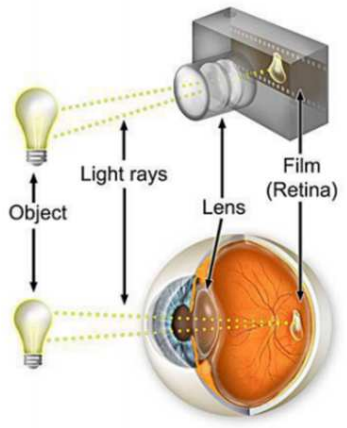

Figure 1. The operation of human eye (source: https://agecomfort . com/product\_images/org \_images/2013/07/Cataract-Pic-1.jpg)

\section{Eye motion types}

Eye motion enables to get information about important details of our environment. It is usually the consequence of the unconscious motion of the eyes. The aim of eye motion is to position the object's image into the sharp vision area by the so-called fixation. We can distinguish several eye motion types based on the direction of eye motion [9]

(1) Fixation: focusing on a particular point.

(2) Tremor: vibrating motion, 'trembling'.

(3) Drift: sliding, so-called vestibo-ocular motion. It is responsible for maintaining fixation on objects.

(4) Saccadic: quick, jump-like motion from one point to another.

(5) Vergens: opposite direction motion

From the above mentioned eye motion types, fixation and saccadic motion play a major role in examination describing eye motion parameters. In the following parts of the article, an examination related to IT problem solving is introduced and evaluated by eye motion analysis.

Former examinations based on eye tracking related to learning

A system based on eye tracking may be well used to research the efficiency of learning processes. Lately, many have made such researches. Porta evaluated the student's eye motion data in a study researching learning experience, 
where examination of learning experiences was performed using an adaptive system. [10] Schmidt-Weigand examined the correlation between textual and visual elements in a multi-media learning material. Based on the eye motion data of nine students, he demonstrated that the visual distribution of learning material was primarily text-driven. [11] Within the ADELE project, Pivec developed a monitoring framework, whose goal was to track the student's eye motion while processing e-learning contents. Moreover, there are ongoing researches about analyses related to eye tracking systems regarding learning processes. [12]

\section{Correlation between the number of fixations and cognitive activities}

We have learnt from the last chapter, that from the eye motion parameters recorded during solving the given IT task, some were influenced by the level of prior knowledge. However, from these eye motion parameters, the number of fixation is more significant, while former researches revealed, that during solving a complex task (such as complex search task), the number of fixation depends on the complexity of the task [13], [14], [15].

There is also a correlation between the number of fixations and the activity level of cognitive activity [16], [17]. In other studies, the number of fixations was presented as a measuring number indicating higher level of attention [18], [19]. As a summary, the number of fixations may be related to the attention-raising nature of an object [20], which is in connection with the prior knowledge required to solve the task during the performance of a problem solving task.

\section{Research of the correlation between the number of fixations and prior knowledge}

\section{The aim of the research}

The aim of the research is to examine, that during solving a task related to computer networks, are there any differences in the eye motion parameters depending on the prior knowledge. The test question related to computer networks can be seen in Figure 2. To perform the analysis of fixation counts defined as the goal of the research, building up a test environment was necessary. The study aimed to examine, whether there were differences in the number of fixations (from the parameters describing eye motion), in case of groups having different prior knowledge regarding solving the problem. 
What is the problem in this topology?

a) Interface configuration of Router R2 or PC4 and PC5

b) Port status on Router R2

c) Cable type between Router R2 and PC4 and PC5

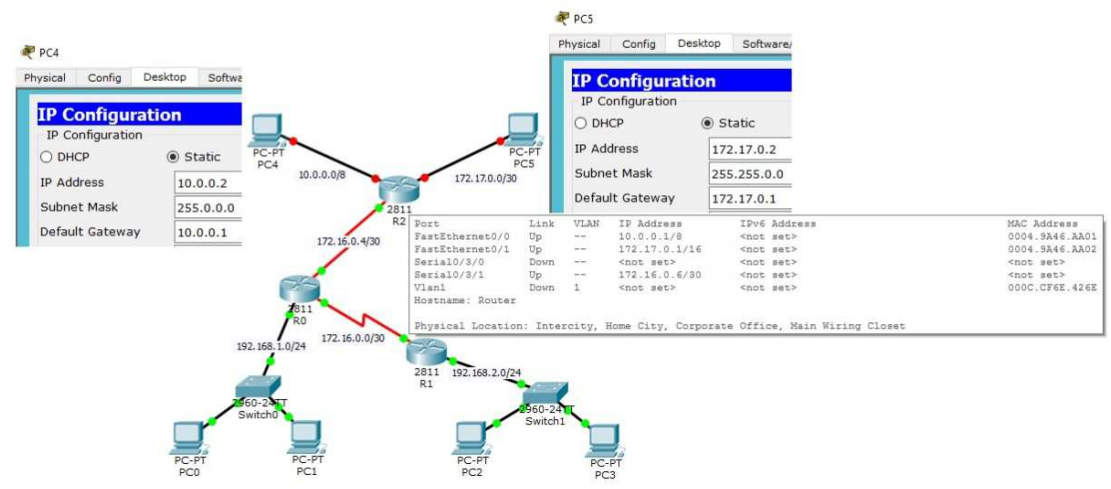

Figure 2. Test question related to computer networks

\section{Testing subjects}

In the study, 32 graduated or school-leaver IT specialists participated, who had to solve a task about computer networks. In the experiment, the group of participating testing subject consisted of volunteers from professional colleagues, current and former students of the University of Dunaújváros, students participating in IT OKJ training, who reported themselves healthy. The participants of the study were primarily representing the younger generation, and there was also a foreign students among them. The gender distribution of the students: 28 males and 4 females. Their age all varied between 20 and $30(\mathrm{~m}=24.2, \mathrm{SD}=2.9)$.

\section{Test environment}

\section{Eye Tribe}

A video-based, portable eye tracking tool, enabling to track the eye look, and measures may be performed on parameters describing eye motion. The tool operates by infra-red (NIR) detection. The tracker consists of two main components: a camera and a high-resolution infra-red LED. The camera tracks the user's eye motion, including minor motions. The camera's sensors can also operate under different light conditions. The device operates in $30 \mathrm{~Hz}$ and $60 \mathrm{~Hz}$ sample rate 
mode with an average accuracy of $0.5^{\circ}$ and spatial accuracy (RMS) of $0.1^{\circ}$. Its operational range varies between 45 and $75 \mathrm{~cm}$. The tool is shown in Figure 3.

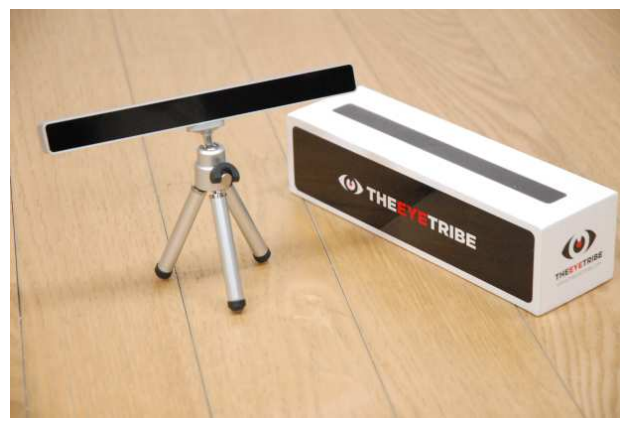

Figure 3. The Eye Tribe

\section{O.G.A.M.A}

O.G.A.M.A is a software analysing eye and mouse cursor motion. It can co-operate with several eye tracking systems. It is suitable for database-driven pre-processing, and filtering of eye and mouse motion data. The measured data may be exported to text or, depending on the module, video format. Data may be displayed and evaluated in several ways, so the software contains several (10) modules, accordingly. The tool is shown in Figure 4.

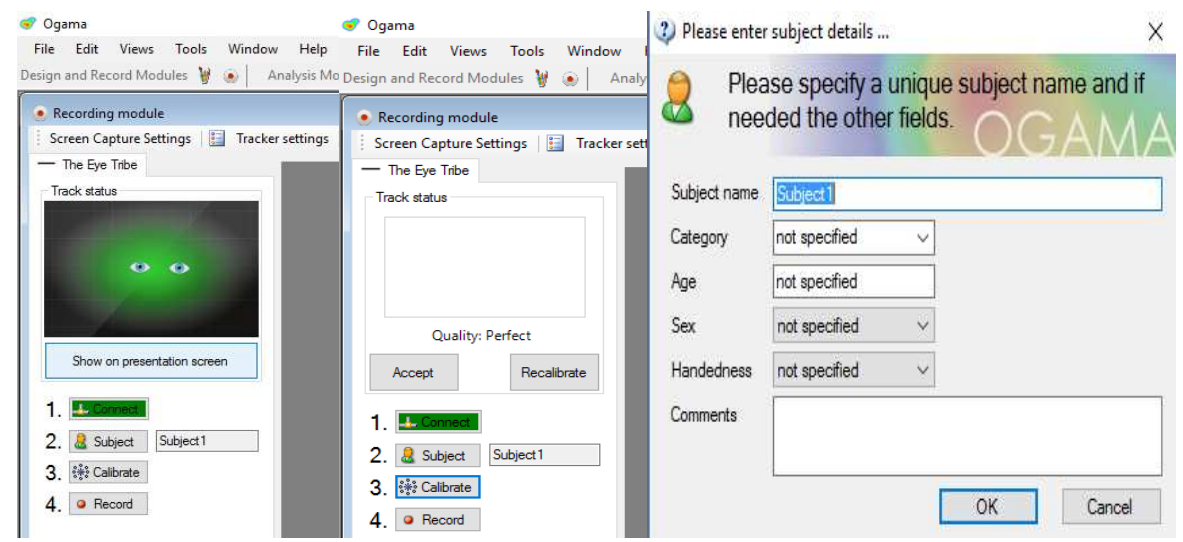

Figure 4. The Recording module of O.G.A.M.A. 


\section{Performance of tests}

Prior to the performance of the tests, testing subjects had to complete a test about computer networks, which was then evaluated. According to the answers given on the test by the testing subjects (max. 10 points), according to their prior knowledge, they were classified into three groups: (0-3 points: LTA - Lower Than Average), (4-6 points: A - Average), (7-10 points: BTA - Better Than Average). According to the test results, 13 people were placed into the Average, 11 into the Lower than Average, and 8 into the Better than Average group. Prior to the beginning of the first test, testing subjects had to sit in front of the computer performing eye tracking. Then, using the OGAMA software, a calibration was performed first. If the calibration was successful, the test was performed. During the test, a task about computer networks appeared on the display, where the correct one could be selected by moving the mouse cursor. The first test was finished by selecting the answer believed to be correct. The post-processing of the data was performed following the tests.

In the next step, the correlation between prior knowledge and the number of fixations were evaluated using statistical analysis. The statistical evaluation of data was performed using the SPSS 21 software package. In case of normal data distribution, Shapiro-Wilk (S-W) normality test was performed. Statistical evaluation of the number of fixation of groups made upon prior knowledge was performed using T-test. The statistical examination of correlation between prior knowledge and the number of fixations was also evaluated. In normal distribution data line, Pearson correlation test was performed to analyse the correlation between the two data lines, while in non-Gauss distribution samples, Spearman correlational coefficients were performed. In case of the applied statistical tests, $\mathrm{p} \leq 0.05$ value was considered as significant.

\section{Results}

The following part of the paper will be assessed that groups having different prior knowledge to detect significant differences between the fixation number using statistical analysis. Using the Independent T-test analysis the means between two unrelated groups on the same continuous variable is compared. In the other hand correlation analysis was used to investigate the relationship between the prior knowledge and the fixation number. 


\section{T-test analysis}

Fixation count of three different group, LTA, A and BTA is analyzed by Ttest. The fixation count is measured on a continuous scale. The independent variable consists of two categorical, independent groups, in the first case it is the LTA and A and the second one it is the A and BTA. There is no relationship between each group because the LTA, A and BTA groups contains different participants in each with no participant being in more than one group.

\section{Outlier analysis}

First the outlier, data point that does not fit the general trend of your data, is detected by plotting the fixations on a graph and visually inspecting the graph for outlier points. Descriptive and Boxplot is used to identify outliers as extreme values (marked with a star). In the analysis a step of $1.5 \times$ Interquartile range (IQR) is used to detect extreme values. The results are shown in Figure 5, Figure 6 and Figure 7.

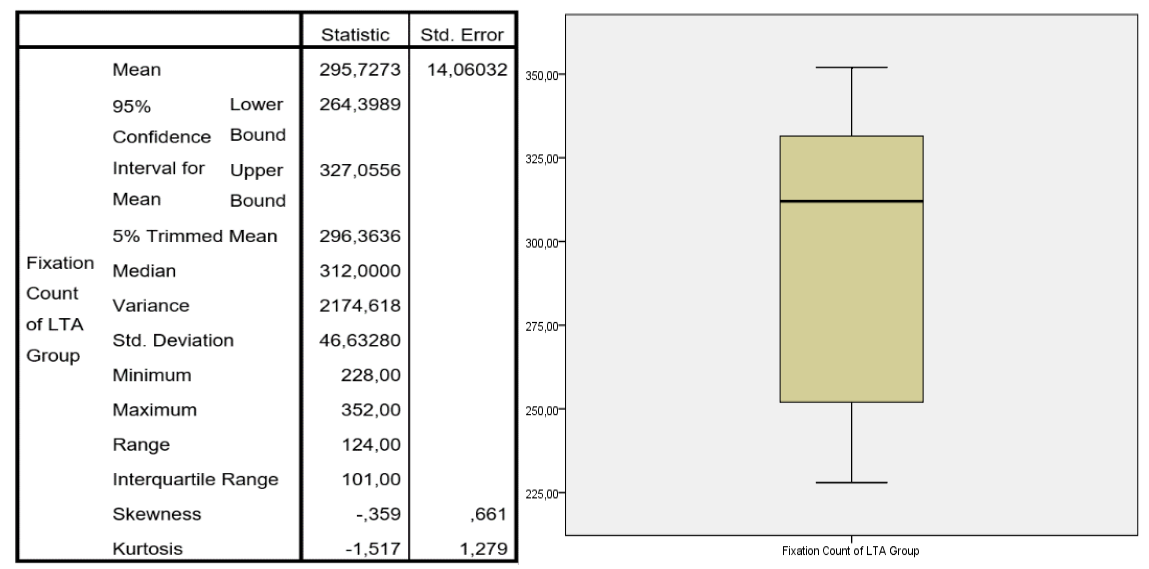

Figure 5. Descriptives and Boxplot of fixation counts of LTA Group

According to descriptives of fixations the Mean=295.7, IQR=101, Maximum=352 and Minimum=228 and figure of Boxplot there is no outlier for LTA Group. 


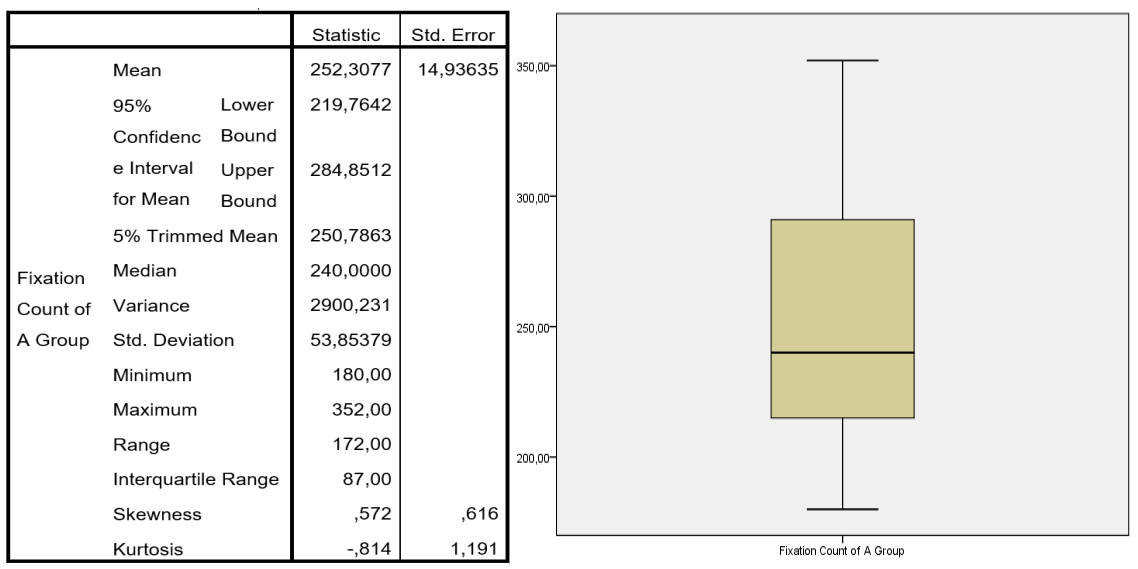

Figure 6. Descriptives and Boxplot of fixation counts of A Group

According to descriptives of fixations the Mean=252.3, IQR=87, Maximum= 352 and Minimum=180 and figure of Boxplot there is no outlier for A Group.

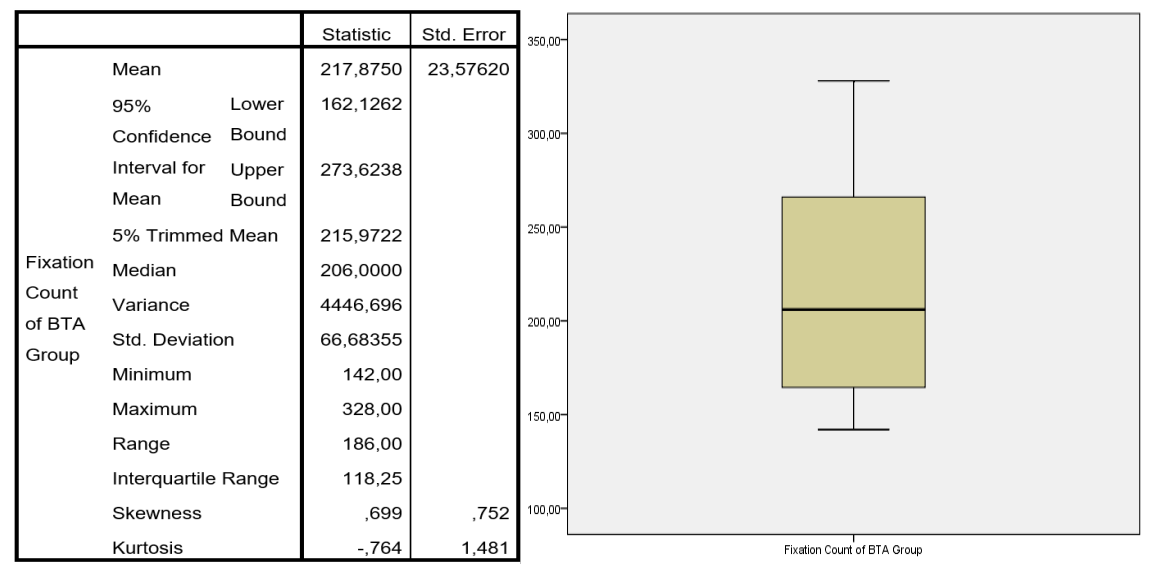

Figure 7. Descriptives and Boxplot of fixation counts of BTA Group

According to descriptives of fixations the Mean=217.9, IQR=118, Maximum=328 and Minimum=142 and figure of Boxplot there is no outlier for BTA Group. 


\section{Test of normality}

The examined variable, fixation count, it should be approximately normally distributed for each group. The independent T-test only requiring approximately normal data because it is quite "robust" to violations of normality.

The normality is analyzed using graphical Q-Q Plot and numerical ShapiroWilk test because this test is more appropriate for small sample sizes $(<50$ samples).The results are shown in case of LTA Group in Figure 8.

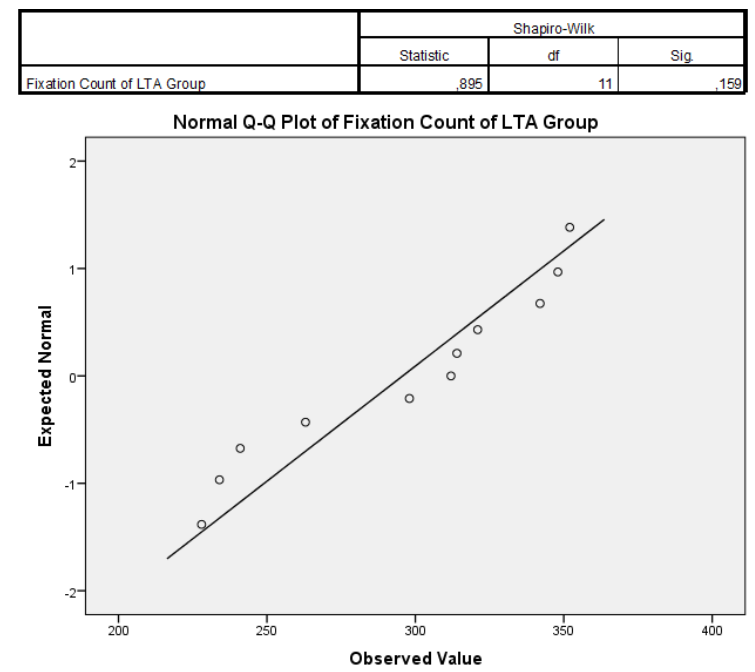

Figure 8. Results of Shapiro-Wilk and Q-Q Plot normality test of fixation counts for LTA Group

The results are shown in case of A group in Figure 9.

The results are shown in case of BTA group in Figure 10.

It can be seen in the results of Shapiro-Wilk Tests that significance values are greater $(0.159,0.43,0.416)$ than 0.05 , so the data is normal for LTA, A and BTA Group also. As it can be seen in the Q-Q Plots, the data points are close enough to the diagonal line, not stray from the line too much, so the data is normally distributed. 


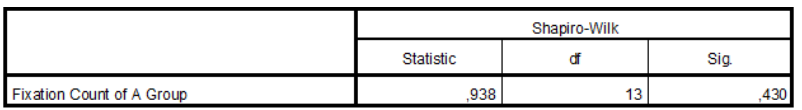

Normal Q-Q Plot of Fixation Count of A Group

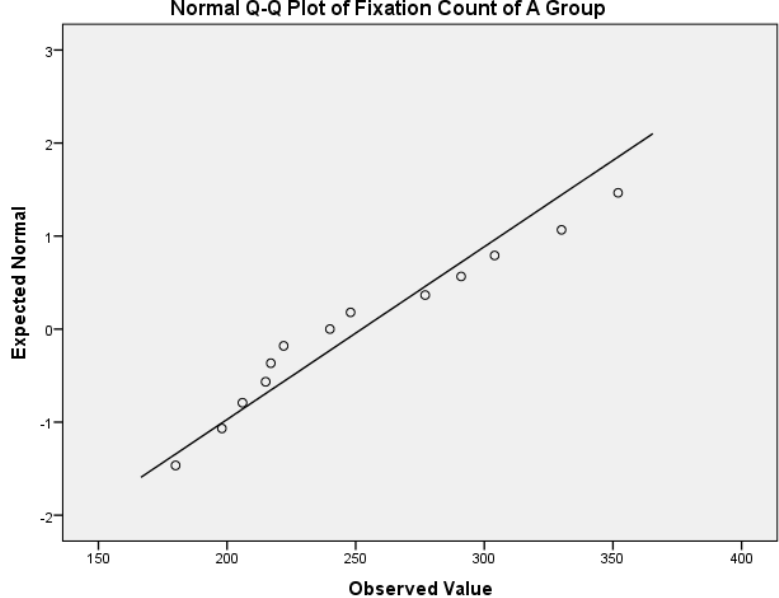

Figure 9. Results of Shapiro-Wilk and Q-Q Plot normality test of fixation counts for A Group
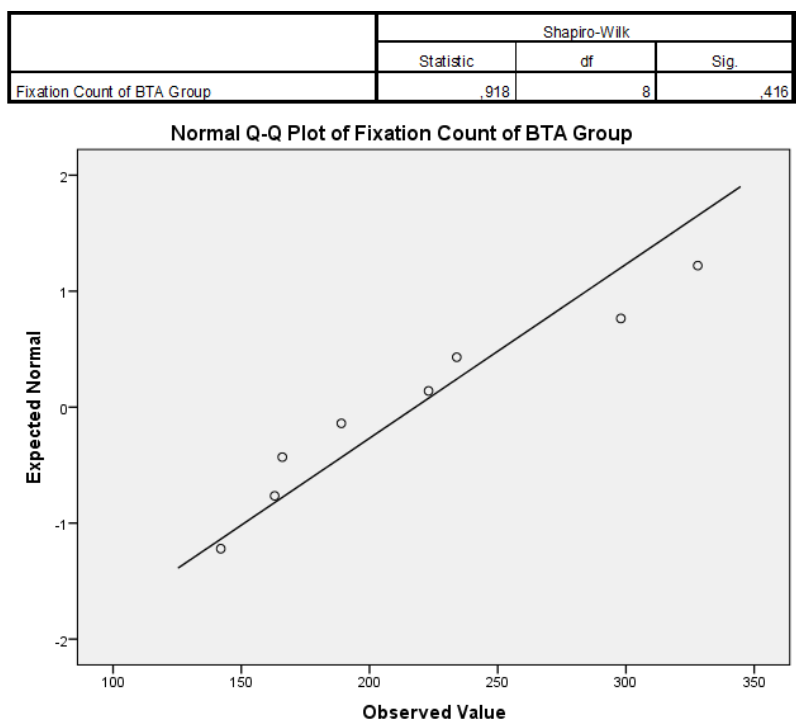

Figure 10. Results of Shapiro-Wilk and Q-Q Plot normality test of fixation counts for BTA Group 


\section{Test of homogeneity of variances}

For using T-test it needs to be homogeneity of variances. Levene's test can be used for analyze the homogeneity of variances. Levene's test is basically an ANOVA test. The results of Levene's test can be seen in Table 1 .

Table 1: Results of Levene's tests for LTA-A, A-BTA Group

\begin{tabular}{|c|c|c|c|c|c|c|c|}
\hline Levene Statistic & df1 & df 2 & Sig. & Levene Statistic & df1 & df 2 & Sig. \\
\hline 308 & 1 & 22 & .584 & 339 & 1 & 19 & 567 \\
\hline
\end{tabular}

Levene's tests showed that the variances of fixations for LTA-A group are equal, $\mathrm{F}(1,22)=0.308, \mathrm{p}=0.584$ and A-BTA also $\mathrm{F}(1,19)=0.339, \mathrm{p}=0.567$ because the significances are greater $(0.584,0.567)$ than 0.05 . So these variables are meet the homogeneity of variance.

\section{Independent T-test}

Using the results of previous tests it can be assessed for the fixation count variable that there is no outlier data, the data is normal for all group and the homogeneity of variances are equal for LTA-A and A-BTA. So the independent T-test can be applied. The results of T-tests can be seen inTable 2 .

Table 2: Results of T-tests for LTA-A, A-BTA Group

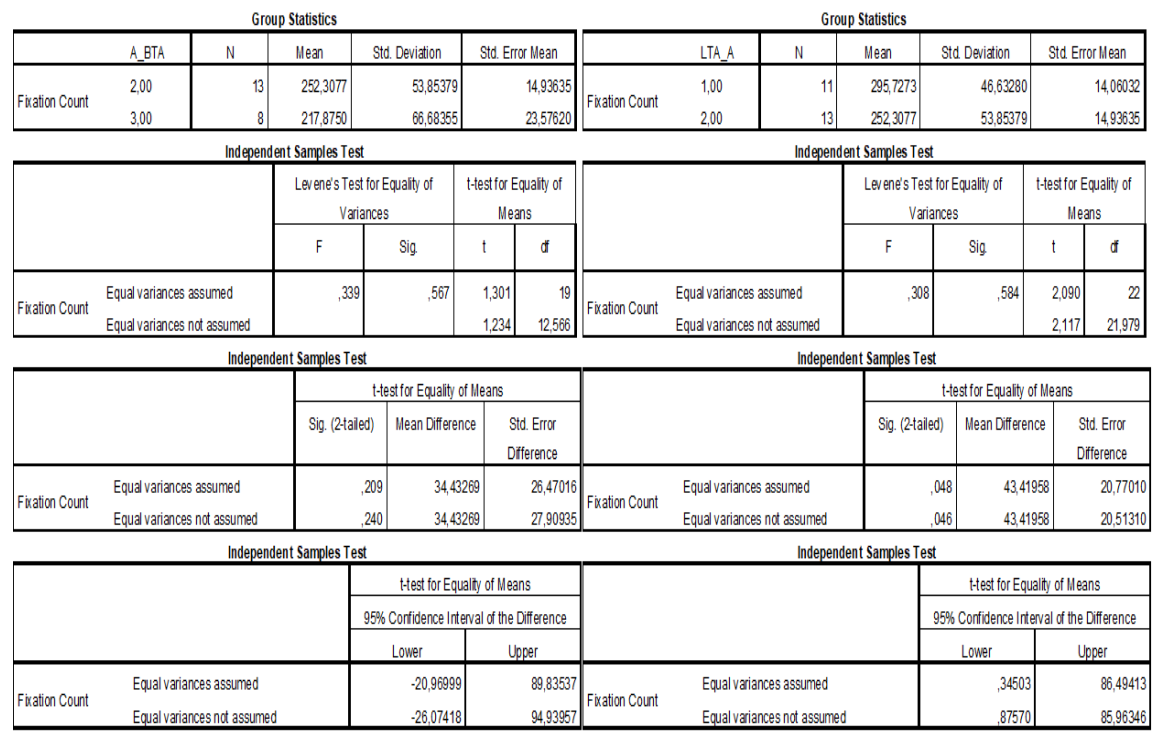

The Group Statistics presents the information on the mean and standard deviation. It can be seen that the means of LTA and A groups are statistically 
significantly different because the significance value (2-tailed) is less than 0.05 . Looking at the Group Statistics table, it can be seen that those who had lower pretest levels had greater fixation count. Similar can be observed for means of A and BTA groups, but the means of A and BTA groups are statistically significantly not different because the significance value (2-tailed) is greater than 0.05 .

\section{Correlation analysis}

The goal of the correlation analysis is to determine the strength and direction between the pre-test results as previous knowledge and fixation. The pre-test and fixation count variables was used to calculate correlation. In case of normally distributed scale data (interval or ratio) and linear relationship Pearson's correlation can be used. The Pearson's correlation coefficient indicates how far away all data points are from the best fit line thereby determining the strength and direction of relationship.

\section{Outlier analysis}

In case of Pearson's correlation test there should be no significant outliers, which are do not follow the usual pattern of the data. Descriptive and Boxplot is used to identify outliers as extreme values (marked with a star). The results are shown in Figure 11 and Figure 12.

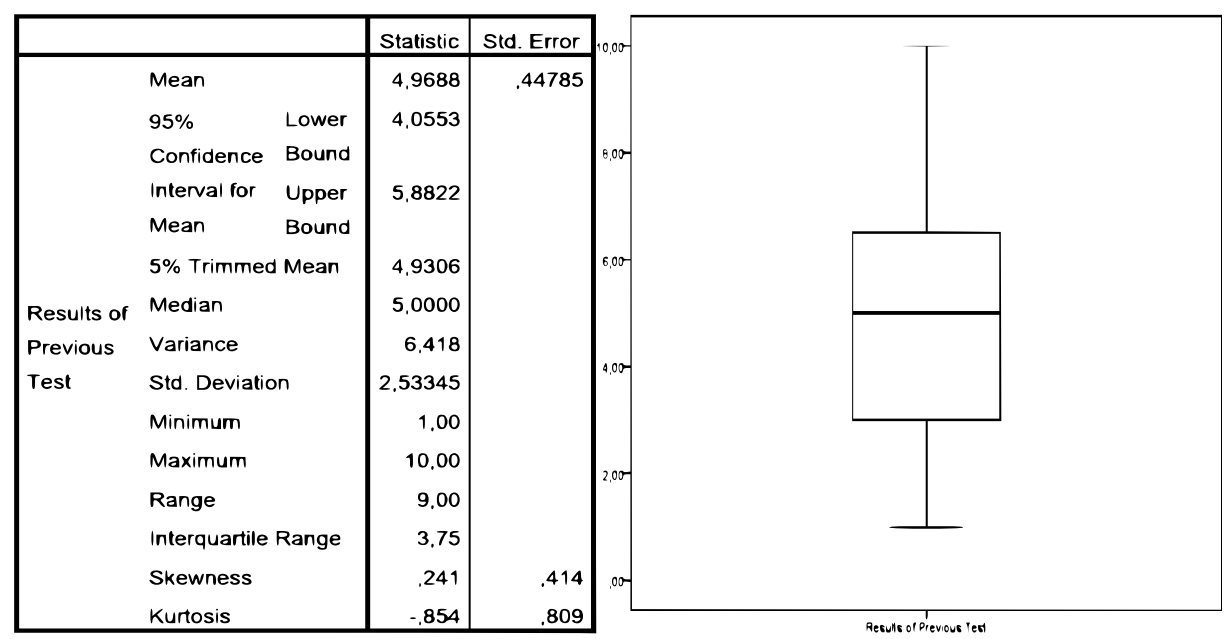

Figure 11. Descriptives and Boxplot of previous test results 
According to descriptives of fixations the Mean=4.97, IQR=3.75, Maximum= 10 and Minimum=1 and figure of Boxplot there is no outlier for previous test results.

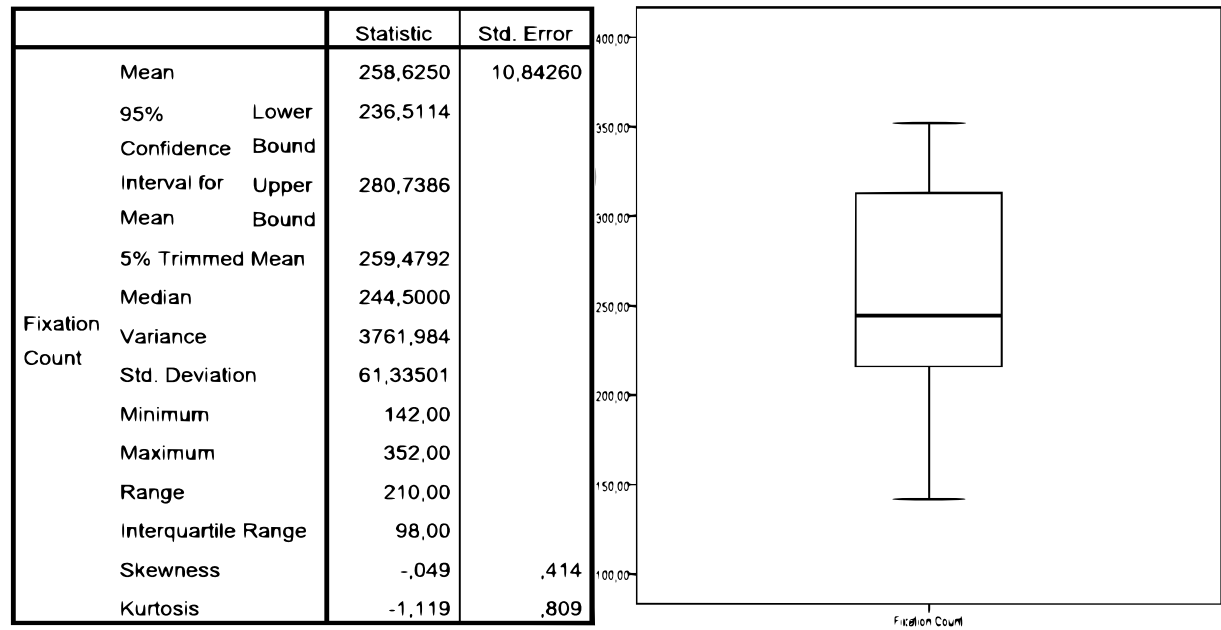

Figure 12. Descriptives and Boxplot of fixation counts

According to descriptives of fixations the Mean=258.62, IQR=98, Maximum=352 and Minimum=142 and figure of Boxplot there is no outlier for fixation counts.

\section{Test of normality}

The variables should be approximately normally distributed. The test of normality was examined same as described previously using Shapiro-Wilk test. The results are shown in Figure 13. 


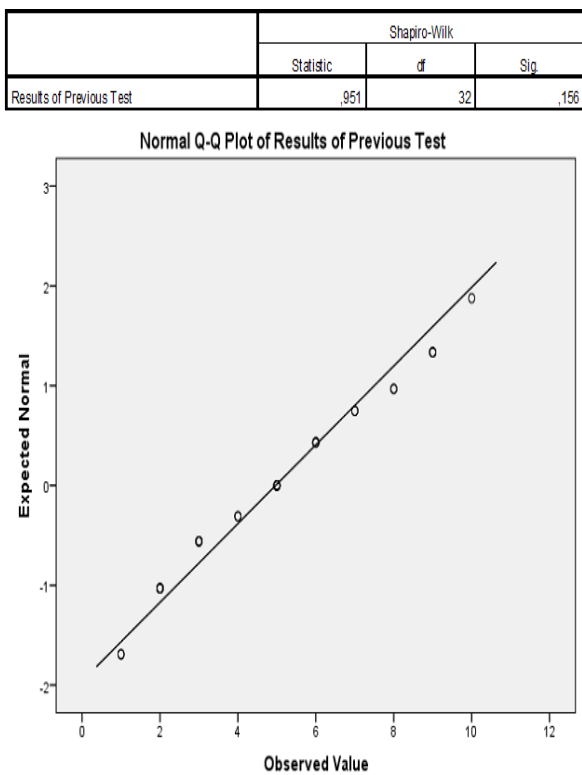

\begin{tabular}{|c|c|c|c|}
\hline & & giroW & \\
\hline & Statitialic & $d f$ & Sig. \\
\hline Yition Count & .95 & & \\
\hline
\end{tabular}

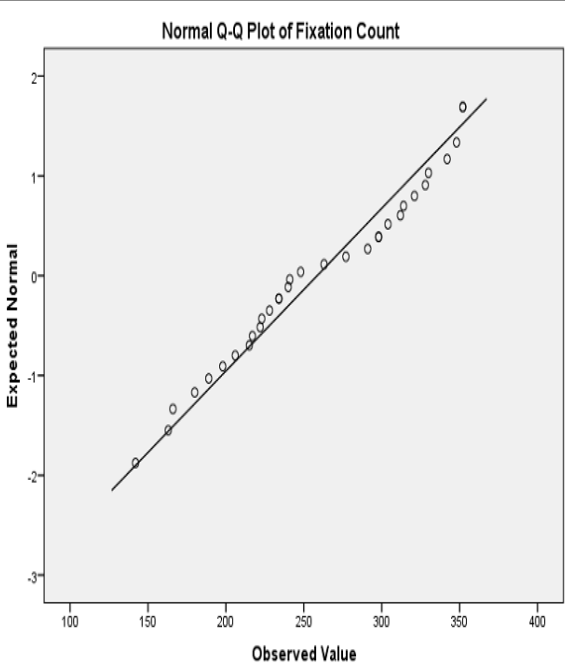

Figure 13. Results of Shapiro-Wilk and Q-Q Plot normality test for previous test results and fixation counts

It can be seen in the results of Shapiro-Wilk Tests that significance values are greater $(0.156,0.174)$ than 0.05 , so the data is normal.

\section{Test of linearity}

Pearson's correlation attempts to draw a line of best fit through the data of two variables, so this method assumes there is a linear relationship between the two variables. Linearity is not an assumption of Pearson's correlation, but it is not expedient to use the Pearson's correlation to determine the strength and direction of a linear relationship when it is known that the relationship between your two variables is not linear. A scatterplot shows the data of one variable against the other, and it can be used to visually inspect the approximate relationship. The scatterplot of previous test results and fixation counts can be seen in Figure 14 . 


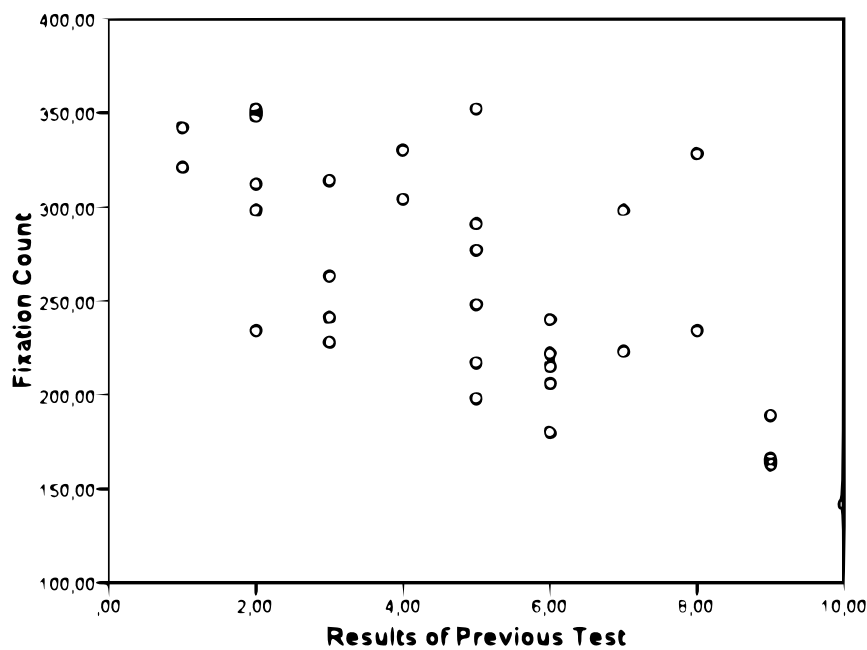

Figure 14. Scatterplot of previous test results and fixation counts

In the scatterplot the approximately best fit line is displayed with thick line. It can be seen that linear relationship is applicable.

Pearson's correlation analysis

The results of Pearson's correlation between previous test results and fixation count can be seen Figure 15.

\begin{tabular}{|ll|r|r|}
\hline & \multicolumn{1}{|c|}{$\begin{array}{c}\text { Results of } \\
\text { Previous Test }\end{array}$} & Fixation Count \\
\hline \multirow{2}{*}{ Results of Previous Test } & Pearson Correlation & 1 & $-.660^{*}$ \\
& Sig. (2-tailed) & & .000 \\
& $\mathrm{~N}$ & 32 & 32 \\
& Pearson Correlation & $-.660^{*}$ & 1 \\
Fixation Count & Sig. (2-tailed) & .000 & \\
& $\mathrm{~N}$ & 32 & 32 \\
\hline
\end{tabular}

•. Correlation is significant at the 0.01 level (2-tailed).

Figure 15. Results of Pearson's correlation

The Pearson correlation coefficient is $\mathrm{r}=-0.66$, and that it is statistically significant $(\mathrm{p}=0.000)$ so the strength of relationship is moderately strong and the direction is negative. 


\section{Conclusions}

This study found that who had LTA levels in the previous test had statistically significantly greater fixation count $(295.72 \pm 46.63)$ compared to who had A levels $(252.3 \pm 53.85), \mathrm{t}=2.09, \mathrm{p}=0.048$. But who had A levels in the previous test had statistically not significantly greater fixation count (252.3 \pm 53.85$)$ compared to who had BTA levels $(217.87 \pm 66.68), \mathrm{t}=1.301, \mathrm{p}=0.209$.

A Pearson's correlation was used to determine the relationship between pre test results showing previous knowledge and fixation count during solving an IT test. There was a moderately strong, negative correlation between pre test results and fixation count, which was statistically significant $(\mathrm{r}=-0.66, \mathrm{n}=32, \mathrm{p}=.000)$.

Based on the changes of eye motion's fixation parameters and its statistical evaluation, it is clear that this eye motion parameter in regards testing subjects with different prior knowledge varies accordingly. This is believed to be the results of the fact, that the look of testing subjects with lower level of prior knowledge often return to each object, in order to understand the task and figure out the solution.

Results of eye motion give us an opportunity in the future to define the correlation between the success or failure to solve a problem and the prior knowledge of the testing subject. The results may provide useful information to check the effectiveness of learning (Gögh, Kovács, \& Sziládi, 2017), so these tools and methods may become the essential part of the future educational infrastructure.

Result of this research help to make the learning materials and additional contents to adaptive. Based on eye movement parameters it can be conclude that the learner is uncertain while learn a curriculum or solve a test, in that case the learning support system could make available more information about the knowledge material for better understanding and learning results.

\section{Acknowledgements}

This publication is supported by the EFOP-3.6.1-16-2016-00003 project. The project is co-financed by the European Union.

\section{References}

[1] J. Katona, Examination and comparison of the EEG based Attention Test with CPT and T.O.V.A., in: Proceedings of 15th IEEE International Symposium on 
Computational Intelligence and Informatics, IEEE, Budapest, Hungary, 2014, $117-120$.

[2] J. Katona, The examination of the application possibilities of brain wave-based control, DUF Press, Dunaújváros, 2015, 167-176.

[3] G. Sziládi, A. Kővári, Gesztusvezérlésen alapuló ember-számítógép interfészek, Dunakavics 4 (2016), 63-73.

[4] K. Bíró, G. Molnár, D. Pap, Z. Szűts, The impact of virtual and augmented learning environments on the teaching and learning process in secondary and higher education, USA, IEEE, 2017, 371-376.

[5] S. Hari, S. Jaswinder, Human Eye Tracking and Related Issues: A Review, International Journal of Scientific and Research Publications 2, no. 9 (2012), 1-9.

[6] B. C. Hewett, V. Strong, ACM SIGCHI curricula for human-computer interaction, New York, NY, USA, ACM, 1992.

[7] G. Bárdos, L. Détári, T. Hajnik, J. Kiss, K. Schlett, K. Tárnok, I. Világi, Élettani gyakorlatok, ELTE, Budapest, 2012.

[8] T. Ujbányi, G. Sziládi, J. Katona, A. Kővári, Pilot application of eye-tracking to analyze a computer exam test, Topics In Intelligent Engineering and Informatics, Springer, 2018, 323-341.

[9] H. Ko, D. M. Snodderly, M. Poletti, Eye movements between saccades: Measuring ocular drift and tremor, Vision Research 122 (2016), 93-104.

[10] M. Porta, Implementing eye-based user-aware e-learning. CHI'08 Extended Abstracts on Human Factors in Computing Systems, ACM, 2008, 3087-3092.

[11] S.-W Florian, K. Alfred, G. Ulrich, A closer look at split Visual attention in system-and self-paced instruction in multimedia learning, Learning and Instruction 2, no. 20 (2010), 100-110.

[12] P. Maja, C. Trummer, J. Pripfl, Eye-tracking adaptable e-learning and content authoring support, Informatica (2006), 83-86.

[13] R. K. Jacob, K. Karn, Eye Tracking in Human-Computer Interaction and Usability, in: H. J., R. R., D. H., The Mind's Eye: Cognitive and Applied Aspects of Eye Movement Research, Elsevier Science, Amsterdam, 2003, 573-605.

[14] J. Goldberg, J. Helfman, Visual scanpath representation, in: Proceedings of the 2010 Symposium on Eye-Tracking Research and Applications, ACM, Oracle USA, 2010, 203-210.

[15] J. H. Goldberg, P. X. Kotval, Computer interface evaluation using eye movements: methods and constructs, International Journal of Industrial Ergonomics 24, no. 6 (1999), 631-645.

[16] S.Geise, Eyetracking in Communication and Media Science: Theory, Method and Critical Evaluation, SCM - Studies in Communication and Media, 2011, 149-263.

[17] K. Holmqvist, M. Nystrom, R. Andersson, Eye Tracking: A Comprehensive Guide to Methods and Measures, Oxford University Press, United Kingdom, 2015, 560.

[18] G. Bente, Erfassung und Analyse des Blickverhaltens, Lehrbuch der Medienpsychologie, Hogrefe, Goettingen, 2004, 297-324. 
[19] M. Rötting, Parametersystematik der Augen- und Blickbewegungen flir arbeitswissenschafiliche Untersuchungen, Germany, 2001.

[20] C. Ehmke, S. Wilson, Identifying web usability problems from eye-tracking data, in: Proceedings of the 21 st British HCI Group Annual Conference on People and Computers: HC1...but not as we know it - Volume 1, BCS-HCI '07, British Computer Society, Swinton, UK, 2007, 119-128.

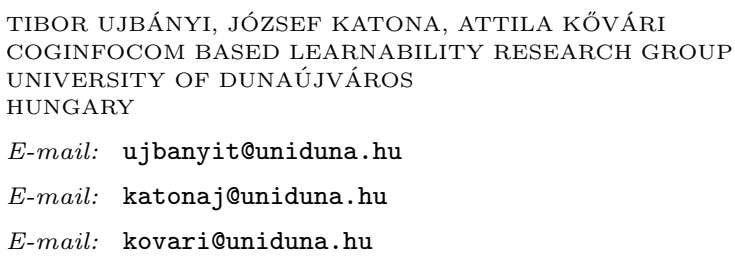

(Received April, 2018) 